\title{
Atypical antipsychotics and the negative symptoms of schizophrenia
}

\author{
David J. King
}

The concept of positive and negative symptoms in schizophrenia can be traced back to Hughlings Jackson (1889) who taught that disease does not create, it sets free, and accordingly positive symptoms could be seen as 'release' phenomena resulting from 'dissolution' of the highest cerebral centres of the nervous system. Crow (1980) revived the dichotomy and proposed a Type I syndrome, characterised by positive symptoms, and a Type II syndrome, characterised by negative symptoms. He thought the latter was due to cortical atrophy and responded poorly to antipsychotic medication. In their review of the distinction, Walker \& Lewine (1988) found a stronger relationship between premorbid dysfunction and negative symptoms than with positive symptoms. They also found there was a stronger influence of genetic factors on negative symptoms than positive symptoms.

The neurophysiology of negative symptoms can best be understood as arising from lesions in the dorsolateral prefrontal cortex and the inability of this higher region to respond to stress (producing negative symptoms), leading to sub-cortical dopamine hyperactivity (producing positive symptoms) (Weinberger, 1987). From functional neuroimaging there is evidence of reduced regional cerebral blood flow in the dorsolateral prefrontal cortex of schizophrenia (Weinberger et al, 1986), and animal studies have shown that lesions in either the frontostriatal or temporal-limbic circuits result in increased dopamine transmission in the basal ganglia (Jaskiw \& Weinberger, 1992).

Although three-syndrome (Liddle, 1987) and even four-syndrome (Harvey et al, 1996; Mellers et al, 1996) models of schizophrenic symptomatology have been proposed, psychomotor poverty or social withdrawal, that is, a 'negative' syndrome, continues to be identified. Since all such studies derive from factor analyses, it is not clear whether we are dealing with separate but overlapping entities or a continuum.

This may be why the literature on the response of negative symptoms to antipsychotic medication is inconsistent. Several authors have argued that people suffering with negative symptoms respond to antipsychotic drug treatment, but others disagree and even suggest such symptoms are exacerbated by such medication. Perhaps an important variable is dose, which could determine the net effect (Baldessarini et al, 1988). Another is the possibility of confusing primary and secondary negative symptoms. The latter (also known as the neuroleptic-induced deficit syndrome) arise mainly from drug-induced extrapyramidal symptoms (EPS), sedation or depression (see Box 1). The importance of recognising such drug-related impairments of affective, cognitive and social functioning is increasingly accepted together with the expectation that new 'atypical' antipsychotics will cause less

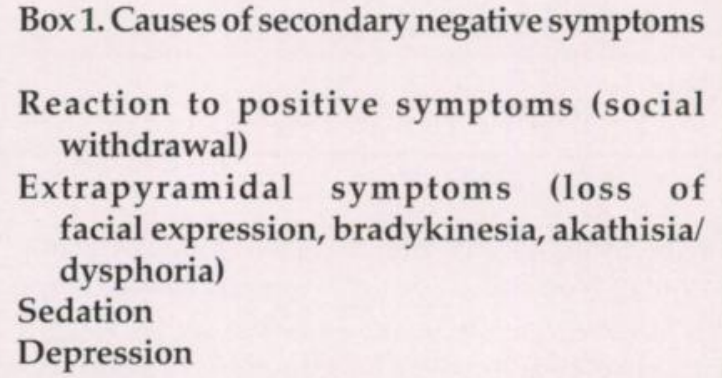

Box 1. Causes of secondary negative symptoms

Reaction to positive symptoms (social withdrawal)

Extrapyramidal symptoms (loss of facial expression, bradykinesia, akathisia/ dysphoria)

Sedation

Depression

David J. King is Professor of Clinical Psychopharmacology in the Queen's University of Belfast Department of Therapeutics and Pharmacology (Whitla Medical Building, 97 Lisburn Road, Belfast BT9 7BL) and was also Consultant Psychiatrist with responsibility for 36 intensive psychiatric care beds in a general adult psychiatric hospital (Holywell Hospital, Antrim) for 21 years. His principal research interests are the biology and neuropsychology of schizophrenia and the pharmacology of antipsychotic drugs. Currently he is engaged in clinical trials of new atypical antipsychotics, the effects of antipsychotics on eye movements, attention and memory in healthy volunteers, and the development of animal models of psychosis. 
impairment in these areas. Nevertheless, Carpenter et al (1988) have also emphasised the importance of delineating primary enduring negative symptoms, in order to distinguish a real drug effect on deficit symptoms from a reduction in neuroleptic-induced symptoms. Very few clinical trials had done this and a European working group has published guidelines for such studies of drug effects on negative schizophrenic symptoms (Möller et al, 1994). They proposed the following six key recommendations for trials of negative symptoms in schizophrenia:

(a) Exclusion of a high level of positive symptoms.

(b) Core negative symptoms (flat affect and poverty of speech) present for at least six months.

(c) Low level of secondary negative symptoms (depression, sedation, EPS) and assessed during the study.

(d) Placebo control.

(e) Duration of at least eight weeks.

(f) Specific negative symptom rating scales and a Clinical Global Impression (CGI) scale should be included.

While there is no definite agreement on the classification of schizophrenic symptoms, there is a general consensus that psychomotor agitation, motor excitement, hallucinations, delusions and thought disorder are regarded as positive symptoms, whereas blunted affect, poverty of speech, loss of drive (avolition) and anhedonia are considered negative symptoms (see Box 2). Further general agreement has emerged that the core negative symptoms are flattened affect and poverty of speech (Barnes, 1994; Möller et al, 1994). Incongruity of affect has been more controversial since it has not always been distinguished from flattening (for example in the Brief Psychiatric Rating Scale (BPRS; Overall \& Gorham, 1962) and early versions of the Manchester Rating Scale (Krawiecka et al, 1977)).

\section{The atypical antipsychotics}

There is no generally accepted definition of 'atypical' (see Box 3) but it is agreed that clozapine is the prototype. In so far as other drugs resemble clozapine biochemically, pharmacologically or clinically, they have been called 'atypical'. There is, nevertheless, no agreement as to how close this resemblance to clozapine needs to be. The principal clinical features which should differentiate atypical antipsychotics from the traditional antipsychotics are: low potential for inducing EPS, superiority in ameliorating negative schizophrenic symptoms, and efficacy in treatment-resistant schizophrenia.
Box 2. Principal negative schizophrenic symptoms (DSM-IV)

*Flat affect

*Alogia (poverty of speech)

Avolition

Anhedonia

( ${ }^{*}$ Core symptoms)

Despite some differences in in vitro receptor binding profiles (see Box 4) no clear clinical differences between the new atypicals have emerged. All appear to be better tolerated than classical antipsychotics. In terms of efficacy in treatment-refractory patients or in negative symptoms, clozapine remains the best established. This must not be confused with potency, however, which is a pharmacological concept referring to the mass of drug required to produce a $50 \%$ maximal response. Using an arbitrary cut-off of a mean daily dose of $100 \mathrm{mg} /$ day, the majority of atypicals are, in fact, low-potency drugs (see Box 4). Only risperidone has been compared directly with

Box 3. Definitions of atypical antipsychotic properties.

Chemical

Different chemical structure from classical antipsychotics

Pharmacalogical

- Evidence of limbic selectivity

Electrophysiology (no depolarisation inactivation in striatal areas - VTA9)

Early gene (e.g.cFOS) activation confined to limbic areas

Animal behaviour (wide separation of dose-response curves for apomorphine-induced hyperactivity and stereotopy)

Reduced elevation of serum prolactin Reduced induction of EPS in primates

- Low dopamine $\left(D_{2}\right)$ receptor occupancy in effective therapeutic dose range

\section{Clinical}

Reduced incidence of EPS

Reduced or zero risk of tardive dyskinesia Improved efficacy in treatment-refractory patients

Improved efficacy in negative symptoms 
Box 4. Classification of atypical antipsychotics

Selective dopamine $\mathrm{D}_{2}$ antagonists

Sulpiride, amisulpride

Mixed $\mathrm{D}_{2}, 5-H T_{2}, \alpha_{1}$, antagonists

Risperidone, zisprasidone, sertindole

Broad spectrum receptor antagonists

Clozapine, zotepine, olanzapine, quetiapine

Low potency (mean doses $>100 \mathrm{mg} /$ day)

Amisulpride, clozapine, quetiapine,

sulpiride, ziprasidone, zotepine

High potency (mean doses $<100 \mathrm{mg} /$ day)

Olanzapine, risperidone, sertindole

clozapine to date. It has been shown to be equally effective but better tolerated than clozapine in acute exacerbations of chronic schizophrenia. Bondolfiet al (1996) reported an eight-week study in 86 treatment-resistant or intolerant patients with chronic schizophrenia, in which risperidone (6 mg/ day) was found to have equivalent efficacy to clozapine ( $300 \mathrm{mg} /$ day). However, true unresponsiveness was not distinguished from intolerance to previous conventional neuroleptics in that study.

This review will consider the evidence on the efficacy of the atypical antipsychotics, currently marketed or in phase III trials, against negative symptomatology. No direct comparisons between these drugs is possible because of wide methodological differences between studies.

\section{Clozapine}

Following the publication of a comparative trial in which clozapine was more effective than chlorpromazine in people with refractory schizophrenia (Kane et al, 1988), clozapine has been licensed for the treatment of people with schizophrenia who are resistant or intolerant to conventional antipsychotics. It must, however, be initiated in hospital and regular leukocyte and differential white cell counts must be undertaken. Both clozapine and chlorpromazine improved total and positive symptomatology in this large double-blind trial of hospitalised people with DSM-III (American Psychiatric Association, 1980) schizophrenia (Kane et al, 1988), but only clozapine significantly decreased the BPRS score for the individual negative symptoms: emotional withdrawal, uncooperativeness, blunted affect, disorientation and psychomotor retardation and for the anergia item of the BPRS (which combines four of these negative symptoms, that is, all except 'uncooperativeness'). The score for EPS on the Simpson-Angus Scale (Simpson \& Angus, 1970) was also significantly reduced in patients taking clozapine compared with those on chlorpromazine, despite the use of prophylactic benztropine in the chlorpromazine group. This points to one of two weaknesses in this otherwise robust and seminal study: no distinction can be made between effects on primary and secondary negative symptoms. The second problem was that there was no specific negative symptom scale used.

Breier et al (1994) aimed specifically to address the issue of whether clozapine beneficially affected primary negative symptomatology. In this study, 39 people who had residual negative and/or positive symptoms ('partial responders') and a low level of EPS, after an open prospective six-week trial of fluphenazine, randomly received double-blind clozapine or haloperidol for 10 weeks. Overall, psychopathology improved in both treatment groups, but the Scale for the Assessment of Negative Symptoms (SANS;Andreasen, 1982) score decreased by $6 \%$ in the clozapine group and increased by $11 \%$ in the haloperidol group. However, the differences between the two treatment groups was not significant in 11 people with deficit schizophrenia (primary enduring negative symptoms). The authors concluded that while clozapine was superior to haloperidol for treating residual positive symptoms, the effects on negative symptoms were quite minor, and they attributed these to a differential effect on secondary symptoms.

\section{Risperidone}

Risperidone was developed following studies which showed that the negative symptoms of schizophrenia and EPS were improved when ritanserin, a selective antagonist at the structurally similar 5- $\mathrm{HT}_{2}$ and 5- $\mathrm{HT}_{1 \mathrm{C}}$ receptors, was combined with haloperidol. As well as being a dopaminergic antagonist, risperidone is an antagonist at $5-\mathrm{HT}_{2}$ receptors.

A beneficial effect of risperidone on negative symptoms had been reported in early comparative trials against haloperidol or perphenazine but there were no significant differences in efficacy between risperidone and the comparators. In contrast, the improvement in the negative sub-scale of the Positive and Negative Syndrome Scale (PANSS; Kay et al, 1989) was significantly greater in patients 
receiving risperidone $6 \mathrm{mg} /$ day than that in those receiving placebo, together with a trend towards superiority to haloperidol in an eight-week, multicentre, double-blind, Canadian study (Chouinard et al, 1993). Fixed doses of risperidone $(2,6,10$ or $16 \mathrm{mg} /$ day) were compared with haloperidol $(20 \mathrm{mg} /$ day) and placebo in 135 people with both positive and negative symptoms. Scores on the Extrapyramidial Symptom Rating Scale (ESRS; Chouinard et al, 1980) increased with the dose of risperidone. The authors suggested that this increase in EPS, which arises because of a shift in the balance between 5- $\mathrm{HT}_{2}$ and $\mathrm{D}_{2}$ antagonism at higher doses, may explain the bell-shaped doseresponse curve of risperidone both for negative and total symptomatology. The findings of an identical study carried out at 20 centres in the USA involving 388 hospitalised patients with DSM-III-R schizophrenia and a PANSS rating between 60 and 120, were similar (Marder \& Meibach, 1994).

A number of subsequent additional analyses of the data from these North American studies have been published, including the use of post hoc analysis of variance and path analysis, to attempt retrospectively to control for the effects on positive symptoms and EPS. One of these suggested that the improvement in negative symptoms occurred in parallel with changes in EPS, but two supported an independent effect on total negative PANSS scores.

Another very large multinational double-blind trial of fixed doses of risperidone $(1,4,8,12$ and $16 \mathrm{mg} /$ day) versus haloperidol ( $10 \mathrm{mg} /$ day) for eight weeks in 1362 people with chronic schizophrenia (DSM-III-R) was reported by Peuskens et al (1995). On the negative sub-scale of PANSS, there was a mean decrease of 5.5 for patients receiving the $4 \mathrm{mg}$ dose, but the differences between this group and those in all other treatment groups (including haloperidol) were not significant. Similarly, on the anergia factor of the BPRS there were no significant inter-group differences, although again improvement tended to be greater in the 4 and $8 \mathrm{mg} /$ day groups. The authors suggested that lower doses of risperidone may be more effective against negative symptoms than higher doses, but no attempt was made to distinguish between primary and secondary negative symptoms. This study has also been criticised for not excluding the effects of washout from previous antipsychotics, particularly depot drugs.

Thus, the best evidence for efficacy on negative symptoms was from the North American study (Marder \& Meibach, 1994) in which the comparators were placebo and a relatively high dose of haloperidol (20 mg).

Only some of the trials described above were able to demonstrate that risperidone was more effective in the amelioration of negative symptomatology than a classical antipsychotic. Furthermore, as with the clozapine studies, none was specifically designed to differentiate between primary and secondary symptoms, and in those studies in which a significant difference was apparent, improvements may have been largely related to the decrease in EPS.

\section{Zotepine}

Zotepine is another putative atypical antipsychotic, which is marketed in some countries including Japan and Germany and is in phase III clinical trials in others. It has shown affinity for a wide range of animal-derived receptors in in vitro binding studies and a marked affinity for both $D_{1}$-like and $D_{2}$-like cloned human receptors. The antipsychotic effect of zotepine has been confirmed in several open trials and in double-blind comparative European trials against perazine and haloperidol. Further large double-blind trials showing efficacy in both acute exacerbations and long-term relapse prevention have also been reported.

Zotepine has also been shown to have superior efficacy to haloperidol against negative symptoms in a double-blind, randomised comparison in 30 people with schizophrenia of the residual type (DSM-III-R) with significant negative symptomatology (Barnas et al, 1992). In addition to SANS, subjects were also evaluated using the BPRS and CGI. Zotepine, but not haloperidol, significantly reduced the average CGI score after 21 days and the anergia factor of the BPRS. When the total SANS scores were analysed both treatments had a significant effect, with a decrease of approximately 24 and $14 \%$ in the zotepine and haloperidol groups, respectively. However, while haloperidol failed to improve any of the individual SANS factors, zotepine significantly decreased the ratings for flattening of affect, alogia, social withdrawal and attention deficit.

To date, over 1.7 million people have been treated with zotepine, but as with clozapine and risperidone, while an effect on negative schizophrenic symptoms has been demonstrated, evidence for an effect on primary symptomatology independent of changes in positive symptomatology and/or EPS is currently lacking.

\section{Sertindole}

Sertindole is an antipsychotic with a pharmacological profile similar to that of risperidone. In early 
placebo-controlled clinical trials, 28 days' treatment with sertindole $(8,12$ and $20 \mathrm{mg} /$ day) showed comparable efficacy with haloperidol ( $16 \mathrm{mg} /$ day) in all measures (PANSS, BPRS and CGI) including those of negative symptoms. A multi-centre doseranging study of four doses $(8,16,20$ and $24 \mathrm{mg} /$ day) of sertindole and one dose of haloperidol $(10 \mathrm{mg})$ in 617 people with schizophrenia in 11 European countries has also been reported. Sertindole ( $16 \mathrm{mg}$ ) was significantly more effective than haloperidol in reducing PANSS negative symptom sub-scale scores, but once again primary and secondary negative symptoms cannot be distinguished. Sertindole was licensed in the UK in July 1996 for the treatment of schizophrenia, but problems with effects on cardiac conduction (increased QTc intervals) may reduce the possibility of adequately addressing the issue of negative symptoms.

\section{Olanzapine}

Olanzapine, an antipsychotic with pharmacology similar to that of clozapine, was also licensed in the UK in 1996. To date no adverse haematological effects have been reported. The results of a large, six-week placebo-controlled comparison of olanzapine at three dosage levels with haloperidol (10-20 mg/day) in 335 people with schizophrenia in acute exacerbation have recently been described (Beasley et al, 1996). At the highest dose used (12.5$17.5 \mathrm{mg} /$ day) olanzapine produced a significantly greater improvement in the SANS rating than either haloperidol or placebo. The low dose (2.5$7.5 \mathrm{mg}$ ) also had a greater effect on SANS ratings than placebo. EPS occurred less frequently at all dosage levels than with haloperidol. A path analysis of this trial has also been published which estimates that $55 \%$ of the superior efficacy of high-dose (mean $15 \mathrm{mg}$ /day) olanzapine to placebo on negative symptoms can be attributed to a direct effect.

\section{Quetiapine}

Quetiapine has a broad receptor binding profile with low to moderate affinity for $\mathrm{D}_{1}, \mathrm{D}_{2}, 5-\mathrm{HT}_{1 \mathrm{~A}}$ and $5-\mathrm{HT}_{2 \mathrm{~A}}$ receptors (with greater affinity for $5-\mathrm{HT}_{2 \mathrm{~A}}$ than for $D_{2}$ receptors); moderate affinity for $\alpha_{1}$ and $\alpha_{2}$ adrenergic receptors; high affinity for $\mathrm{H}_{1}$ receptors but little or no muscarinic binding and no effects on prolactin. Its antipsychotic efficacy has been established in four placebo-controlled trials and a comparison with chlorpromazine. Three of these have been summarised by Hirsch et al (1996). These were all in patients with acute exacerbations of chronic or sub-chronic schizophrenia and of short duration (three weeks in one and six weeks in the others). A number of phase III trials have also been completed but none of these has specifically addressed negative symptoms, although an ongoing trial is examining efficacy in patients resistant to treatment.

In one placebo-controlled study in which both a low (up to $250 \mathrm{mg} /$ day) and a high (up to $750 \mathrm{mg}$ / day) dose range were compared with placebo in 286 patients, significant superiority was found for the higher dose range in patients from the USA (who were assessed by the SANS), but not in those from Europe (who were assessed by the PANSS). No statistically significant difference was found in the comparison study between similar doses of quetiapine and chlorpromazine (up to $750 \mathrm{mg}$ daily) for six weeks in 201 patients using the PANSS negative symptom sub-scale, although the improvement was greater in the quetiapine group. Two further placebo-controlled studies in which the SANS was used to measure negative symptoms, have also been reported in which the superiority of quetiapine to placebo appears to be demonstrated.

\section{Ziprasidone}

Ziprasidone, a potent antagonist of dopamine $D_{2}$ and 5-HT receptors, is currently being studied in phase III clinical trials. In a six-week trial of 302 people with acute exacerbations of schizophrenia or schizoaffective disorder, ziprasidone ( 80 or $160 \mathrm{mg} /$ day) was significantly superior to placebo with respect to both positive and negative symptoms (BPRS, PANSS, CGI severity; Reeves, 1996; Tandon et al, 1997). There are currently no published studies involving active comparators.

\section{Amisulpride}

Amisulpride is chemically related to sulpiride and has a high affinity for $D_{2}$ and $D_{3}$ receptors, particularly at limbic sites, but is devoid of activity at other receptors. One hundred and four hospitalised patients with schizophrenia (DSM-III) with predominant severe negative symptoms after a 6to 12-week washout period, participated in a larger amisulpride study (Boyer $e t$ al, 1995), which was a multi-centre, double-blind comparison of two 
dosage levels (100 and $300 \mathrm{mg} /$ day) with placebo over six weeks. The mean total SANS score of 97 at baseline was reduced by $22.8 \%$ in the placebogroup, $40.6 \%$ in the $100 \mathrm{mg} /$ day group and $45.9 \%$ in the $300 \mathrm{mg} /$ day group. Differences between the placebo and amisulpride groups were significant overall and for alogia, avolition/apathy and attentional impairment, and there was also a trend towards superiority for affective blunting. Baseline EPS ratings were low and did not change with treatment. The authors note that the effects of amisulpride at the low doses employed in this well-designed study are at variance with the classical antipsychotic effects observed at doses above $600 \mathrm{mg} /$ day.

The most recent study, by Loo et al (1997), compared amisulpride ( $100 \mathrm{mg} /$ day) with placebo in 141 people with DSM-III-R schizophrenia selected on the basis of having predominantly negative symptoms ( $\geq 60$ on the SANS and $\leq 50$ on the Scale for the Assessment of Positive Symptoms (SAPS; Andreasen, 1984)). Drop-out rates were significantly lower in the amisulpride group than in the placebo group both after three ( 29 and $57 \%$, respectively) and six months (45 and 68\%, respectively). There was also a significantly increased proportion of responders ( $\geq 50 \%$ improvement in SANS baseline total score) in the amisulpride group than in the placebo group (42 and $15.5 \%$, respectively) on completion at six months.

These amisulpride studies are particularly persuasive since the patients involved had been carefully selected for primary negative symptoms. These data, together with the low propensity for substituted benzamides (sulpiride, amisulpride and remoxipride) to cause EPS, suggest that these drugs are also atypical antipsychotics. The term has not generally been applied to sulpiride and amisulpride, presumably because the French have preferred to use terms such as 'energising', 'disinhibiting', 'activating' or 'releasing'.

\section{Discussion}

\section{Pharmacology of atypical antipsychotics}

Since clozapine is the prototype atypical, an understanding of the basis for its mode of action is essential in order to develop safer drugs with a similar or improved clinical profile. However, the 'rich' pharmacological profile of this drug makes this an enormous and perplexing task.

The new atypical antipsychotics can be divided arbritarily into three groups on the basis of their receptor binding profiles (Lieberman, 1993; Gerlach \& Peacock, 1995; see Box 4). To date all effective antipsychotics are dopamine $D_{2}$ receptor antagonists; however, $D_{2}$ antagonism is also responsible for the classical EPS. Although selective $D_{2}$ receptor antagonists (sulpiride, amisulpride and remoxipride) are effective antipsychotics, selective $D_{1}$ antagonists are not. The selective $\mathrm{D}_{2}$ antagonists seem to achieve a reduction in EPS by a combination of limbic selectivity, low potency and/or low dosage.

Additional $5-\mathrm{HT}_{2}$ receptor antagonism may be important in reducing the incidence of EPS but it does not necessarily confer any other atypical properties such as an effect on negative symptoms. Selective $5-\mathrm{HT}_{2 \mathrm{C}}$ or $5-\mathrm{HT}_{3}$ antagonists have not been found to be antipsychotic, but a selective $5-\mathrm{HT}_{2 \mathrm{~A}}$ antagonist is currently under investigation as an antipsychotic with particular efficacy in negative symptoms. $5-\mathrm{HT}_{6}$ and $5-\mathrm{HT}_{7}$ receptors have also been cloned and their antagonists may provide further opportunities for new antipsychotics. Other possibly relevant receptors include the central $\alpha_{1}$ and/or $\alpha_{2}$ adrenoceptors. The ultimate hope is to find an antipsychotic which is not a $\mathrm{D}_{2}$ antagonist. In this way EPS can be avoided. However, the property that is required to produce an effect on primary negative symptoms remains elusive.

\section{Efficacy of atypicals on negative symptoms}

The results of the trials of the atypical antipsychotics discussed above suggest that these drugs are superior to the traditional antipsychotics in the treatment of negative schizophrenic symptomatology. However, since negative symptoms may be secondary to positive symptomatology, EPS, depression or sedation, and in the majority of the trials such secondary negative symptoms were not differentiated from the primary negative symptoms of the disease, there is little evidence to substantiate an independent effect of any of the atypical antipsychotics on primary negative symptomatology at the present time. Of the 15 trials summarised in Table 1, only four selected patients with 'predominantly negative symptoms', and the best evidence of efficacy to date appears to be for amisulpride. Nevertheless, those with predominantly negative symptoms may still be a heterogeneous group and a pure 'negative syndrome' occurs rarely, if at all. The Boyer et al (1995) study included a wide range of subtypes of schizophrenia but $55 \%$ of those in the Loo et al (1997) study were of the residual type. In the former study five of the nine drop-outs on placebo were because of 
Table 1. Summary of key double-blind controlled trials of atypical antipsychotics on negative schizophrenic symptoms

\begin{tabular}{|c|c|c|c|c|}
\hline Drug/reference & Comparator & $\begin{array}{l}\text { Duration } \\
\text { (weeks) }\end{array}$ & $\begin{array}{l}\text { Patients with } \\
\text { predomimantly } \\
\text { negative symptoms }\end{array}$ & Outcome \\
\hline \multicolumn{5}{|l|}{ Clozapine } \\
\hline Kane et al (1988) $(n=268)$ & chlorpromazine & 6 & No & clozapine>chlorpromazine \\
\hline Breier et al (1994) $(n=11)$ & haloperidol & 10 & Yes (deficit state) & clozapine=haloperidol \\
\hline \multicolumn{5}{|l|}{ Risperidone } \\
\hline Chouinard et al (1993) $(n=135)$ & placebo & 8 & No & risperidone $>$ placebo \\
\hline Marder \& Meibach (1994) $(n=388)$ & placebo & 8 & No & risperidone $>$ placebo \\
\hline Peuskenset al (1995) ( $n=1362)$ & haloperidol & 8 & No & risperidone $=$ haloperidol \\
\hline \multicolumn{5}{|l|}{ Zotepine } \\
\hline Barnas et al (1992) $(n=30)$ & haloperidol & 7 & Yes & zotepine $>$ haloperidol \\
\hline Petit et al (1996) $(n=126)$ & haloperidol & 8 & No & zotepine $>$ haloperidol \\
\hline \multicolumn{5}{|l|}{ Sertindole } \\
\hline Hale et al (1996) $(n=617)$ & haloperidol & 8 & No & sertindole $>$ haloperidol \\
\hline \multicolumn{5}{|l|}{ Olanzapine } \\
\hline Beasley et al (1996) $(n=335)$ & placebo & 6 & No & olanzapine $>$ placebo \\
\hline \multicolumn{5}{|l|}{ Quetiapine } \\
\hline Hurst \& Link (1996) $\left(\mathrm{n}=308^{1}\right)$ & placebo & 6 & No & quetiapine $>$ placebo \\
\hline \multicolumn{5}{|l|}{ Ziprasidone } \\
\hline Tandon et al (1997) $(n=302)$ & placebo & 6 & No & ziprasidone>placebo \\
\hline \multicolumn{5}{|l|}{ Amisulpride } \\
\hline Boyer et al (1995) $(n=104)$ & placebo & 6 & Yes & amisulpride $>$ placebo \\
\hline Looet al (1997) $(n=141)$ & placebo & 26 & Yes & amisulpride $>$ placebo \\
\hline
\end{tabular}

exacerbations of positive or mixed symptoms, but it is not clear from the report of the latter study whether the drop-outs because of 'lack of efficacy' were associated with positive symptoms or not.

Comparisons with clozapine are not yet possible because only a small series of deficit subjects have so far been studied in a double-blind trial (Breier et al, 1994) and this would not have had sufficient power to show a difference from an active comparator.

There are a number of other factors which confound the clinical interpretation of these trials and make comparisons problematical, the most important of which is the difficulty in defining precisely which symptoms are the core primary negative symptoms. As already noted, a European working group on negative symptoms in schizophrenia (Möller et al, 1994) considered flat affect and poverty of speech to be the core negative symptoms. The four symptoms listed in DSM-IV (see Box 2) - flat affect, avolition, alogia and anhedonia - may be considered to be the key negative features of schizophrenia but take no account of cognitive impairment or social withdrawal. Many of the above trials did not, in fact, specifically aim to examine drug effects on negative symptomatology.

There are also important differences between the various rating scales used in the above trials, mainly the BPRS, PANSS and SANS, that make it difficult to compare the different studies (Barnes, 1994).

There have also been major differences in the people selected: only clozapine and risperidone have been studied in those resistant to treatment, and only clozapine and amisulpride in patients with predominantly negative symptoms.

It should also be recognised that the optimum dose and duration of treatment may be different for negative and positive symptoms. There may also be a longer delay in the response of some negative symptoms compared with positive symptoms. An example of this can be found in a clozapine study where improvement in psychopathology pre-dated cognitive improvement by weeks to months (Hagger et al, 1993).

Another criticism that can be levelled against the majority of comparative trials of the atypical antipsychotics is that the comparator drugs chosen were predominantly those causing a high level of EPS, namely haloperidol and fluphenazine. Many 
of the trials have also used rather high fixed doses of these comparators.

Finally, there is the problem of adequate washout from previous antipsychotic treatment, particularly if this has been with depot drugs. In an unpublished placebo-controlled study of remoxipride in negative symptoms it was found that in $75 \%$ of subjects depot antipsychotic plasma levels were $10 \%$ or more of the baseline values eight weeks after discontinuation, and in about one-third of patients these levels were $50 \%$ or more of baseline values (R. McCreadie, 1997, personal communication). Thus, much of the improvement in negative symptoms seen in the above trials might have been attributable to wash-out from such drugs. Even if the studies were placebo-controlled, no firm conclusions can be drawn unless the two groups are known to have been comparable with respect to both dose and type of pre-trial medication.

The six recommendations for trials of negative symptoms in schizophrenia by Möller et al (1994) go some way towards addressing these issues (see p. 54). To these could be added that the wash-out from depot medication should be for a minimum of three months. This can be done by substituting oral for depot drugs for two months, followed by placebo substitution for a further month.

\section{Conclusions}

Although it has been claimed that the newer, atypical antipsychotics have improved efficacy against the negative symptoms of schizophrenia when compared with the standard antipsychotics, evidence for an effect independent of an improvement in positive symptomatology and/or EPS is poor. The pharmacological profile responsible for any improvement in efficacy has not been fully elucidated but it seems unlikely that only one receptor subtype mediates all atypical effects. Further studies are required to determine whether the atypical antipsychotics do alter the course of negative schizophrenic symptoms or improve the prognosis for the deficit state, and whether there are any important differences between them.

\section{References}

American Psychiatric Association (1980) Diagnostic and Statistical Manual of Mental Disorders (3rd edn) (DSM-III). Washington, DC: APA.

Andreasen, N. C. (1982) Negative symptoms in schizophrenia: definition and reliability. Archives of General Psychiatry, 39, 784 788.
- (1984) Scale for the Assessment of Positive Symptoms. Iowa City, IA: Department of Psychiatry, University of Iowa.

Baldessarini, R. J., Cohen, B. M. \& Teicher, M. H. (1988)Significance of neuroleptic dose and plasma level in the pharmacological treatment of psychoses. Archives of General Psychiatry, 45, 79-91.

Barnas, C., Stuppäck, C. H., Miller, C., et al (1992) Zotepine in the treatment of schizophrenic patients with prevailingly negative symptoms: a double-blind trial versus haloperidol. International Clinical Psychopharmacology, 7, 23-27.

Barnes, T. R. E. (1994) The assessment of negative symptoms. In The Assessment of Psychoses: A Practical Handbook (eds T. R. E. Barnes \& H. E. Nelson), pp. 51-70. London: Chapman and Hall Medical.

Beasley, C. M., Tollefson, G., Tran, P., et al (1996) Olanzapine versus placebo and haloperidol. Neuropsychopharmacology, 14, 111-123.

Bondolfi, G., Baumann, P., Patris, M., et al (1996) A randomised double-blind trial of risperidone versus clozapine for treatmentresistant chronic schizophrenia. European Neuropsychopharmacology, 6 (suppl. 2), 21-25.

Boyer, P., Lecrubier, Y., Puech,A. J.,et al (1995) Treatment of negative symptoms of schizophrenia with amisulpride. British Journal of Psychiatry, 166, 68-72.

Breier, A., Buchanan, R. W., Kirkpatrick, B., et al (1994) Effects of clozapine on positive and negative symptoms in out-patients with schizophrenia. American Journal of Psychiatry, 151, 20-26.

Carpenter, W. T., Heinrich, D. W. \& Wagman, A. M. I. (1988) Deficit and non-deficit forms of schizophrenia: the concept. American Journal of Psychiatry, 145, 578-583.

Chouinard, G., Ross-Chouinard, A., Annable, L.,et al (1980) The extrapyramidal symptom rating scale. Canadian Journal of Neurological Science, 7, 233.

-, Jones, B., Remington, G., et al (1993) A Canadian multicentre, placebo-controlled study of fixed doses of risperidone and haloperidol in the treatment of chronic schizophrenic patients. Journal of Clinical Psychopharmacology, 13, 25-40.

Crow, T. J. (1980) Molecular pathology of schizophrenia: more than one disease process? British Medical Journal, 280, 66-68.

Gerlach, J. \& Peacock, L. (1995) New antipsychotics: the present status. International Clinical Psychopharmacology, 10 (suppl.3), $39-48$.

Hale, A., Van der Burgh, M., Friberg, H. H., et al (1996) Dose ranging study comparing four doses of sertindole and one dose of haloperidol in schizophrenic patients. European Neuropsychopharmacology, 6 (suppl.3), 61.

Harvey, C. A., Curson, D. A., Pantelis, C., et al (1996) Four behavioural syndromes of schizophrenia. British Journal of Psychiatry, 168, 562-570.

Hagger, C., Buckley, P., Kenny, J.-T., et al (1993) Improvement in cognitive functions and psychiatric symptoms in treatmentrefractory schizophrenic patients receiving clozapine. Biological Psychiatry, 34, 702-712.

Hirsch, S. R., Link, C. G. G., Goldstein, J. M., et al (1996) ICI 204, 636: A new atypical antipsychotic drug. British Jourmal of Psychiatry, 168 (suppl. 29), 45-56.

Hughlings Jackson, J. (1889) On post-epileptic states: a contribution to the comparative study of insanities. Journal of Mental Science, $34,490-500$.

Hurst, B. C. \& Link, C. G. G. (1996) 'Seroquel' (ICI 204,636) - efficacy in treating the negative symptoms of schizphrenia. European Neuropsychopharmacology, 6 (suppl. 4), 124.

Jaskiw, G. E. \& Weinberger, D. R. (1992) Dopamine and schizophrenia: a cortically corrective perspective. Seminars in the Neurosciences, 4, 179-188.

Kane, J., Honigfeld, G., Singer, J., et al (1988) Clozapine for the treatment-resistant schizophrenic: a double-blind comparison versus chlorpromazine/benztropine. Archives of General Psychiatry, 45, 789-796.

Kay, S. R., Opler, L. A. \& Lindenmayer, J. P. (1989) The Positive and Negative Syndrome Scale (PANSS): rationale and standardisation. British Journal of Psychiatry, 155 (suppl. 7), $59-67$.

Krawiecka, M., Goldberg, D. \& Vaughan, M. (1977) A standardized psychiatric assessment scale for rating chronic psychotic patients. Acta Psychiatrica Scandinavica, 55, 299-308.

Liddle, P. (1987) The symptoms of chronic schizophrenia: a reexamination of the positive-negative dichotomy. British Journal of Psychiatry, 151, 145-151. 
Lieberman, J. A. (1993) Understanding the mechanism of action of atypical antipsychotic drugs. British Journal of Psychiatry, 163 (suppl. 22), 7-18.

Loo, H., Poirer-Littre, M.-F., Theron, M., et al (1997) Amisulpride versus placebo in the medium-term treatment of the negative symptoms of schizophrenia. British Journal of Psychiatry, 170, 18-22.

Marder, S. R. \& Meibach, R. C. (1994) Risperidone in the treatment of schizophrenia. American Journal of Psychiatry, 15, 825-835.

Mellers, J. D. C., Sham, P., Jones, P. B., et al (1996) A factor analytic study of symptoms in acute schizophrenia. Acta Psychiatrica Scandinavica, 93, 92-98.

Möller, H.-J., van Praag, H. M., Aufdembrinke, B., et al (1994) Negative symptoms in schizophrenia: considerations for clinical trials. Psychopharmacology, 115, 221-228.

Overall, J. E. \& Gorham, D. R. (1962) The brief psychiatric rating scale. Psychological Reports, 10,799-812.

Petit, M., Raniwalla, J., Leutenegger, E., et al (1996) A doubleblind study of zotepine vs haloperidol in schizophrenia. Psychopharmacology Bulletin, 32, 81-87.

Peuskens, J., on behalf of the Risperidone Study Group (1995) Risperidone in the treatment of patients with chronic schizophrenia: a multinational, multi-centre, double-blind, parallelgroup study versus haloperidol. British Journal of Psychiatry, $166,712-726$.

Reeves, K. (1996) The efficacy and safety of two fixed doses of ziprasidone in schizphrenia. European Neuropsychopharmacology, 6 (suppl. 3), 201.

Simpson, G. M. \& Angus, J. W. S. (1970) A rating scale for extrapyramidal side effects. Acta Psychiatrica Scandinavica Supplementum, 212, 11-19.

Tandon, R., Harrigan, E. \& Zorn, S. H. (1997) Zoprasidone: a novel antipsychotic with unique pharmacological and therapeutic potential.Journal of Serotonin Research, 4, 159-177.

Walker, E. \& Lewine, R. J. (1988) The positive/negative symptom distinction in schizophrenia: validity and etiological relevance. Schizophrenia Research, 1, 315-328.

Weinberger, D. R. (1987) Implications of normal brain development for the pathogenesis of schizophrenia. Archives of General Psychiatry, 44, 660-670.

- Berman, K. F. \& Zec, R. F. (1986) Physiologic dysfunction of dorsolateral prefrontal cortex in schizophrenia. I. Regional cerebral blood flow evidence. Archives of General Psychiatry, 43, 114-124.

\section{Multiple choice questions}

1. Clozapine is of proven benefit in:

a treatment-resistant positive symptoms

b treatment-resistant primary negative

symptoms

c treatment-intolerant patients

d secondary negative symptoms

e neuroleptic malignant syndrome.

2. Primary negative symptoms:

a are antipsychotic resistant

b are antipsychotic induced

c are associated with dopamine hyperactivity in the basal ganglia

d may precede positive symptoms

e were first described by Crow (1980).
3. Atypical antipsychotic drugs:

a have a reduced incidence of extrapyramidal symptoms

$b$ are selective dopamine $D_{2}$ or $D_{3}$ receptor antagonists

c are all 5- $\mathrm{HT}_{2}$ antagonists

$\mathrm{d}$ have been shown to have limbic selective actions in pre-clinical tests

e are all effective in primary enduring negative symptoms.

4 A neuroleptic-induced deficit syndrome:

a can be induced by low-potency antipsychotics

b can be associated with cognitive impairment

c is irreversible

d may respond to antidepressants

e may respond to an atypical antipsychotic.

5. The following scales are reliable measures of negative symptoms:

a the Brief Psychiatric Rating Scale (BPRS)

b the Positive and Negative Syndrome Scale (PANSS)

c the Scale for the Assessment of Negative Symptoms (SANS)

d the Clinical Global Impression Scale (CGI)

e the Manchester Rating Scale (MRS). 